\title{
Bioconjugation among Metallopharmaceuticals: A Review
}

\author{
Jan Mohammad Mir, Ram Charitra Maurya*, Washid Khan and Ritesh Chourasia \\ Department of Chemistry, RD University, India
}

Submission: May 05, 2017; Published: June 22, 2017

*Corresponding author: Ram Charitra Maurya, Coordination, Bioinorganic and Computational Chemistry Laboratory, Department of PG Studies and Research in Chemistry \& Pharmacy, RD University, Jabalpur-482001, India, Email: rcmaurya1@gmail.com

\begin{abstract}
This review pertains to an effort to notify the importance of metal binding of naturally occurring molecules. Metallopharmaceutical science is a huge discipline of multifarious applications. In due course of design of metallic drugs one has to rely upon biological relevance of the compound. Sometimes the target activity is lost into toxicity. Hence, the association of a biomolecule or modified bio-compound coordinated with metallic system is the essence of bioconjugation and is the need of hour. Bio-conjugated metallic complexes are always praised for better action. Some diseases have been exemplified in this review and a comprehensive way of presentation has been established throughout the text.
\end{abstract}

Keywords: Bioconjugation; AD; Diabetes; Cancer; Antioxidant

\section{Introduction}

Bioconjugation is a meticulous chemical strategy to form a stable covalent link between two molecules, at least one of which is a biomolecule. Synthesis of bioconjugates involves a variety of challenges, ranging from the simple and nonspecific use of a fluorescent dye marker to the complex design of antibody drug conjugates. Antibody-drug conjugates such as Brentuximab vedotin and Gemtuzumab ozogamicin are examples of bioconjugation, and are an active area of research in the pharmaceutical industry [1]. A promising strategy to enable the use of metal nuclides in antibody-targeted imaging and therapy is to design molecules that coordinate to the metal ion and preclude its release in-vivo [2].

A necessary prerequisite of any ligand that binds a metal to form a contrast agent is that the resulting contrast agent be stable so as to prevent the loss of the metal and its subsequent accumulation in the body. Other considerations include an ability to reversibly bind water, which in turn increases it contrastability and decreases the dose level required. This ability is clearly important since the interaction between any two nuclear spins through space decreases at a rate equal to the reciprocal of the distance raised to the sixth power [3].

Hence, metals in medicine are used in organic systems for diagnostic and treatment purposes. Inorganic elements are also essential for organic life as cofactors in enzymes called metalloproteins. When metals are scarce or high quantities, equilibrium is set out of balance and must be returned to its natural state via interventional and natural methods. Metals play a vital role in an immense number of extensively differing biological processes. Some of these processes are quite specific in their metal ion requirements, in that only certain metal ions in specified oxidation states can accomplish the necessary catalytic structural requirement (Figure 1) [4].

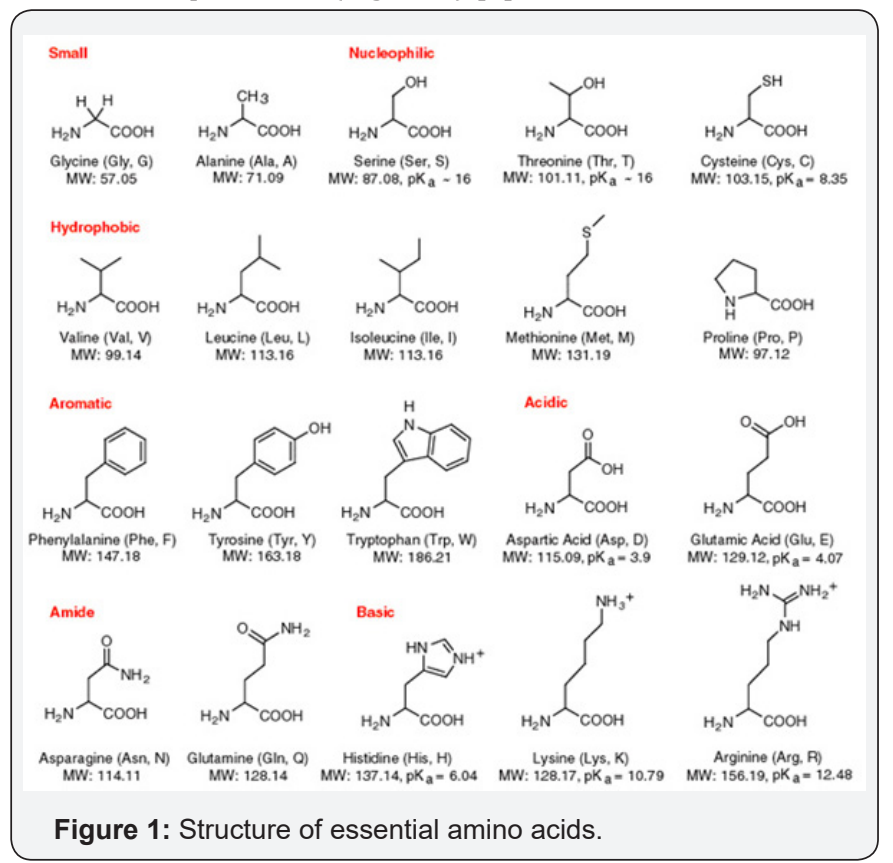

One of the principal themes of bioinorganic chemistry is the synthesis of metal complexes that have the ability to mimic the 
functional properties of natural metalloproteins [5,6]. Proteins, some vitamins and enzymes contain metal ions in their structure involving macromolecular ligands. Inorganic and bioinorganic chemistry are the major contributing fields of medical science and human health witnessed by the past half century. Today, metal-containing therapeutics constitutes a multi-billion dollar industry. Recent investigations in bioinorganic chemistry include the use of metal ions as synthetic scaffolds for the preparation of small molecule therapeutics.

\section{Insulin Mimicry via Metallic Compounds}

In a continued interest towards metallopharmaceuticals (Figure 2) Sodium vanadate and derivatives of bismaltolatooxovanadium (IV) complexes (BMOV) have been reported to lower levels of blood sugar in diabetic patients [7]. In other words it may be said that scientific community is busy with copying a hormone called as insulin to develop an ultimate treatment of diabetes. Recent under trial experiments with Gold and Silver based glucose level stabilizing agents have further unfurled seek for more efficacy $[8,9]$.

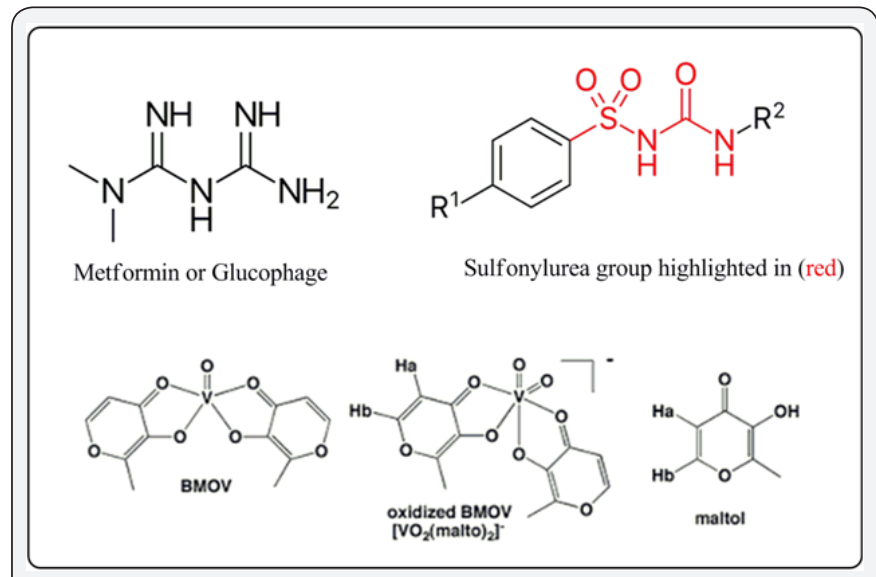

Figure2: Some examples of anti-diabetic drugs.

Antidiabetic drugs may be either insulin injections which are used in serious cases of diabetes or oral hypoglycemic drugs, and are suitable for most adult patients. Different hypoglycemic drugs are available in market. These drugs may be classified as the following: Sulphonylureas: increase insulin secretion and help to reduce blood glucose levels. But sulphonylurea may cause weight gain, hypoglycemia and allergic reactions. They are contraindicated in case of pregnancy, lactation and diabetes type 1 . They act by affecting the pancreatic $\beta$-cells stimulates the movement of insulin-containing secretory granules to the cell surface then into circulation. Biguanides (metformin): They prevent production of glucose in the liver, so improve the body's sensitivity to insulin. They may cause temporary nausea and/or diarrhea, loss of appetite and metallic taste. They are contraindicated with kidney or liver diseases and heart problems. Alpha Glucosidase Inhibitor (Acarbose): They may cause diarrhea, gas, constipation, or stomach pain. Hence, the search for more intelligent/efficient antihyperglycemic or antihypoglycemic agents continues. Dissemination of such area of research expects clinically approved use of metal containing compounds for identifying new medicinal agents from throughout the periodic table to be used as antidiabetic and antioxidant tools.

\section{Biotransformation of Metallic Compounds}

Elemental Medicine is nowadays accepted as a rapidly developing field busy with developing novel therapeutic and diagnostic metal complexes. Advances in biotransformation of metal complexes and targeting, with particular reference to platinum anticancer, gold anti-arthritic, and bismuth antiulcer drugs has remained active goal since decades [10,11]. Studies of iron and copper complexes have shown that they can be more active in cell destruction as well as in the inhibition of DNA synthesis, than the uncomplexed organic ligands [12]. Hence, the field of inorganic chemistry in medicine may usefully be divided into two main categories: firstly, ligands as drugs which target metal ions in some form, whether free or proteinbound; and secondly, metal-based drugs and imaging agents where the central metal ion is usually the key feature of the mechanism of action $[13,14]$. In addition to metal complexes of novel ligands, compounds of metals with already known organic pharmaceuticals like aspirin, paracetamol, metformin, etc. have gained keen interest [15]. It has been seen that their biological relevance increases on complexing with the respective ligands (organic medicinal chelates). Research has shown significant progress in utilization of transition metal complexes as drugs to treat several human diseases like carcinomas, lymphomas, infection control, anti-inflammatory, diabetes, and neurological disorders [16].

Cancer is the second most frequent cause of death in the world. The discovery of antitumor activity of cisplatin began a search for other metal complexes with cytotoxic properties against cancer cells [17]. The instant information regarding anticancer activities of the ten most active metals: arsenic, antimony, bismuth, gold, vanadium, iron, rhodium, titanium, gallium and platinum have been already updated. Despite the efficacy of cancer treatment using cisplatin, the use is still limited due to severe side effects such as neuro-, hepato- and nephro-toxicity and by resistance phenomena [18]. Gold (III)-dithiocarbamato complexes have recently gained increasing attention as potential anticancer agents because of their strong tumor cell growthinhibitory effects, generally achieved by exploiting non-cisplatinlike mechanisms of action [19].

The potential applications of Mo-based complexes in medicinal chemistry as metallopharmaceuticals in treating diseases such as cancer and tumors [20] indicate the emphasis of significant approach of non-platin anticancer agents. Ruthenium compounds are highly regarded as potential drug candidates. The compounds offer the potential of reduced toxicity and can be tolerated in-vivo. The various oxidation states, different mechanism of action, and the ligand substitution kinetics of ruthenium compounds give them advantages over platinum- 
based complexes, thereby making them suitable for use in with promising cytotoxic profiles [21]. The role of transition metals as micronutrients as well as co-factors of several metalloenzymes in living systems further corroborates the rationale behind synthesis and evaluation of novel transition-metal based complexes for their anticancer effects [22]. Future use of substituted organic ligands and their metal complexes would hence bring forth effective anticancer agents and would depend on structural modifications as would afford them better potency against a number of tumors/cancers, together with low toxicity and better solubility.

\section{Antioxidant Properties of Metal Complexes}

An antioxidant is a molecule that inhibits the oxidation of other molecules. Oxidation is a chemical reaction that can produce free radicals, leading to chain reactions that may damage cells. Antioxidants terminate these chain reactions. Transition metal complexes have been shown to possess encouraging antioxidant activities [23]. $\mathrm{Co}(\mathrm{II}), \mathrm{Ni}(\mathrm{II}), \mathrm{Cu}(\mathrm{II})$ and $\mathrm{Mn}$ (II) complexes of 6-bromo-3-(3-(4-chlorophenyl)acryloyl)-2H-chromen-2-one have been recently found to be effective antioxidants [24]. Generally, antioxidant activity of complexes are determined invitro by the hydroxyl radical scavenging, DPPH, NO and reducing power methods [25]. The chemical principles of methods based on biological oxidants comprise superoxide radicals scavenging (02•-); hydroxyl radical scavenging (HO.); hydrogen peroxide scavenging (H2O2); peroxyl radical scavenging (ROO.) and nitric oxide scavenging (NO.) [26]. Among the non-biological testing scavenging of 2, 2-diphenyl-1-picrylhydrazyl radical (DPPH• assay) and scavenging of 2, 2-azinobis-(3-ethylbenzothiazoline6-sulphonate) radical cation (ABTS assay) are mostly experimented. Furthermore, thiobarbituric acid reactive substances (TBARS) and protein carbonyl assays have also been the subject of great attention in this context $[27,28]$. The novel electrochemical approach to antioxidant activity assay based on the reaction with stable radical 2,2'-diphenyl-1-picrylhydrazyl (DPPH) monitored by the rotating disk electrode (RDE) method has been described advantageous in comparison with usual spectrophotometrical assay since it can be applied to colored compounds and in a wide range of concentrations [29].

\section{Dementia Relevant Metallic Systems}

Alzheimer's disease currently affects over 5.4 million Americans with $\$ 236$ billion spent annually on the direct costs of patient care [30]. Studies on antioxidant drugs would surely open successful doors to treat AD patients. Seeking for potential antioxidants, chemical behavior of Quercetin as antioxidant and metal chelator has become the subject of intense experimental research [31]. Under comparative antioxidant studies of $\mathrm{Co}(\mathrm{II}), \mathrm{Ni}(\mathrm{II}), \mathrm{Cu}(\mathrm{II})$ and $\mathrm{Mn}(\mathrm{II})$ complexes of 6-bromo-3-(3(4-chlorophenyl)acryloyl)-2H- chromen-2-one Ni(II) complex shows superior antioxidant activity than other complexes [32]. Commonly it is has been observed that metal complexes may serve as better free radical scavengers [33-35] as compared to the respective free ligands. In some cases antioxidant complexes have rendered a well pronounced larvicidal activity [36]. Hence, synthetic chemistry is playing revolutionary role in human beings by synthesizing novel compounds by different techniques [37]. The target of scientific community has been thus to prepare bioactive compounds relevant to anticancer, antioxidant and enzyme inhibition studies at both the in-vitro as well as in-vivo fronts.

\section{Biomarkers}

Biochemical pathways are famously complex and interconnected, so it's no surprise that depictions of them have to be simplified (Figure 3). Increasingly, molecular and cell biologists have been coming to terms with the fact that it is hard to decide a label for some protein as a green fluorescent protein (GFP) and expect it to carry on as before. Putting a star next to its name on the whiteboard, or renaming it 'Target-GFP', doesn't capture what's really going on. It is very, very hard to observe living systems at the molecular level without perturbing the very things trying to see, but a great deal of effort is now going into trying to minimize these effects [38]. Under the light shed for evaluation of antidiabetic and antioxidant research, besides developing biomarkers treatment strategies have also been the subject of huge interest. The current status of the aimed field in terms of literature survey is discussed below: (Figure 3).

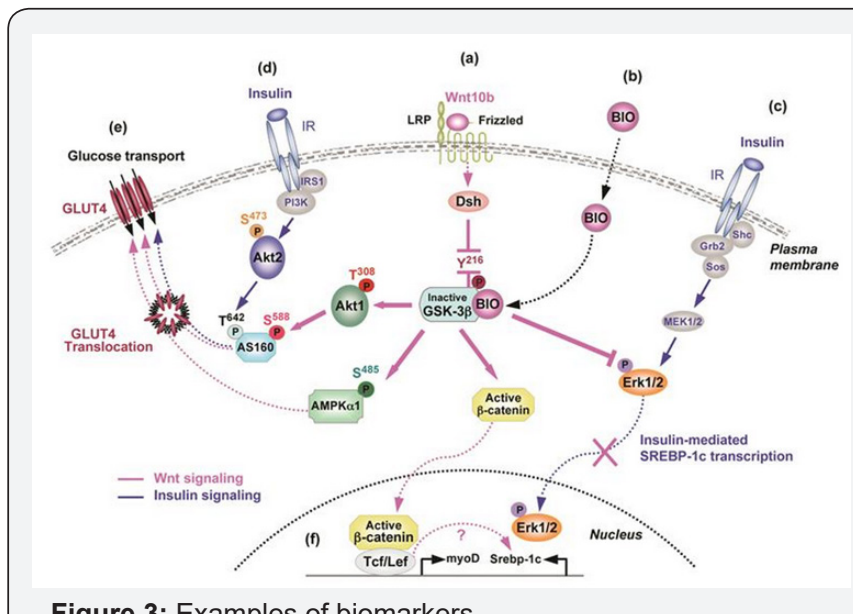

Figure 3: Examples of biomarkers.

\section{Diabetes and Bio-Conjugation}

With the aim to continue the enthusiastic search of metallopharmaceutical drugs against diabetes $[39,40]$, thiazolidinediones (TZD) have been reported to be effective anti-diabetic agents that improve insulin sensitivity through the activation of the nuclear receptor and adipocyte-specific transcription factor, peroxisome proliferator-activated receptor gamma (PPAR- $\gamma$ ) [41]. Recently it has been found that Selective PPAR $\gamma$ modulators $(\mathrm{SPPAR} \gamma \mathrm{M})$ retain insulin sensitizing activity but with minimal side effects compared to traditional TZDs agents [42]. A combination of virtual docking, Surface plasmon resonance (SPR)-based binding, luciferase reporter and adipogenesis assays have been suggested to enlighten 
the interaction mode, affinity and agonistic activity of L312 to PPAR $\gamma$ in-vitro, respectively [43]. The pharmaceutical isoforms having anti-diabetic effect act by improving the biochemical parameters, this effect is probably due to the high content of polyphenolic compounds found in the formulations [44].

In due course of finding a successful antihyperglycemic candidate, metallic compounds like Vanadium complexes have been well demonstrated in streptozotocin-induced (STZ) diabetic rats and was found that that the vanadate and vanadyl forms of vanadium possessed a number of insulin-like effects in various cells [45]. In the current times basic aspect of diabetes including insulin molecular characterization, chemical basis and its secretion, hypoglycemic drugs and their mode of action associated with diabetes are among the main quests being searched [46]. In an approach of comparative antidiabetic studies of isoforms of BMOV having different metallic centres, it has been found that none so far has surpassed bis (maltolato) oxovanadium (IV) (BMOV) for glucose- and lipid-lowering in an orally available formulation [47]. It is hence clear that ligand and metal selection should be meticulously done to formulate efficient antidiabetic compound.

The bioconjugate chemistry of antihyperglycemic metallic complexes have presented worth some results. The conspicuous application of chromium (III)-amino acid complex against nicotinamide-streptozotocin induced diabetic Wistar rats showed that supplementation of $\mathrm{Cr}$ (III)-complex in 8 weeks decreased the blood glucose level in range 46.446-79.593\% [48]. Similarly, vanadyl (IV) adenine complex has been introduced as a new drug model for the diabetic complications [49]. Therefore it is expected to be worthy if derivatives of biogenic ligands are formed to design a ligand of favourable properties. For instance, zinc metal-organic framework (MOF) synthesized under mild hydrothermal routes using 5-aminotetrazole and methyl-2amino-4-isonicotinate anionic ligands has been reported to possess a well pronounced in-vivo antidiabetic activity and low in-vitro cell toxicity [50]. With the same effort,

$\mathrm{N}, \mathrm{N}$-Dimethylbiguanide hydrochloride complexes of Neodymium introduced as oral glucose-lowering agent to treat non-insulin dependent diabetes mellitus and to act as antioxidant has shown prominent effect of functional group position in the respective ligands [51].

The medical properties of naturally occurring compounds such as chromones, flavonoids and coumarins are expected to enhance when complex with metal ions suggest the importance of bioconjugate chemical drug research. These complexes can be successfully used in the satisfactory treatment of diseases such as diabetes mellitus [52]. In recent years regulation of the enzymatic activity of human aldose reductase (HAR) has been the main focus of investigation, due to its potential therapeutic application in Diabetes mellitus (DM). Docking behaviour of human aldose reductase (HAR) with different ligands namely such as embelin (Figure 4), copper-embelin complex, zinc- embelin complex, vilangin and quercetin evaluated along with their putative binding sites using Discovery Studio Version 3.1 has shown that that vilangin has maximum interaction energy $(-48.94 \mathrm{kcal} / \mathrm{mol})$ and metformin with the least interaction energy $(19.52 \mathrm{kcal} / \mathrm{mol})$ as compared to the other investigated ligands [53]. Therefore, it is strongly suggested that such type of study outcomes might provide new insight in understanding these seven ligands, as potential candidates for human aldose reductase (HAR) inhibitory activity \& for the prevention of Diabetes mellitus (DM) associate disorders.

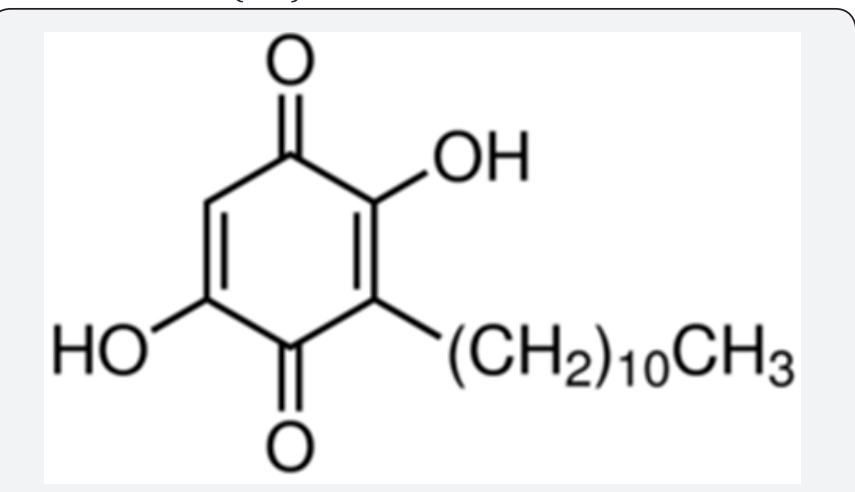

Figure 4: Structure of embelin.

Based on combined in-vitro and in-vivo antioxidant evaluation of resveratrol (Figure 5) and molecular modeling studies, it has been indicated that ligand-target interactions/ biological activities are largely dependent on enantiomerism of a target compound [54].

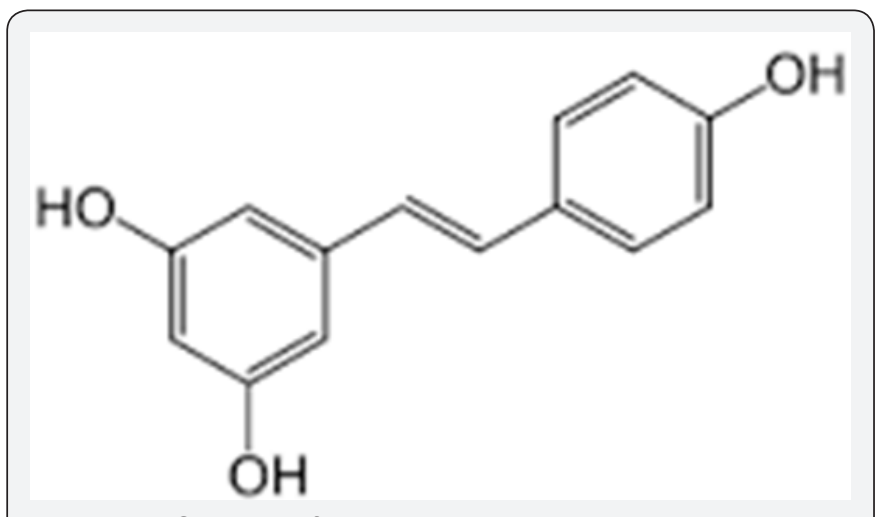

Figure 5: Structure of resveratrol.

\section{Antioxidant Activity and Bioconjugation}

Antioxidant studies are carried out at the cost of various standard methods [55]. Metal dyshomeostasis is known to be linked with numerous diseases such as Alzheimer's and Parkinson's diseases, cancer, etc. Recent studies have indicated that some of the metallic compounds of certain ligands may be active while some render inactivity when antioxidant activity test was carried out using picryhydrazyl (DPPH) [56]. On one hand polyphenols have been suggested as efficient antioxidant and anti inflammatory candidates [57] and on the other hand their metallic compounds are expected to exhibit enhanced antioxidant activity due to flexible oxidation state of a metallic centre [58]. Nickel complex of the non-steroidal anti- 
inflammatory drug diflunisal (Hdifl) resulted in the additive antioxidant effect of the respective ligand [59].

The antioxidant activity of the ligand, bis(N-(3-methoxysalicylidene)-4-amino -phenyl)ether (H2L) and its metal complexes Mn(III) and Cu(II) complexes determined by DPPH, superoxide, hydroxyl and ABTS radical scavenging methods invitro, suggest that the $\mathrm{Cu}(\mathrm{II})$ complex exhibits greater antioxidant activity against DPPH, superoxide, hydroxyl and ABTS radicals than those of the ligand and the Mn(III) complex [60]. The biotin8-hydroxyquinoline conjugates and their metal complexes with manganese(II), cobalt(II), nickel(II), copper(II) and zinc(II) have also been well studied for the possible application in oxidative stress [61]. Similar fashion has been observed with the metallic compounds of

p-coumaric acid [62], 2-(3-amino-4, 6-dimethyl-1Hpyrazolo[ 3,4-b]pyridin-1-yl)aceto-hydrazide [63], chromone Schiff base (Figure 6) [64], etc.

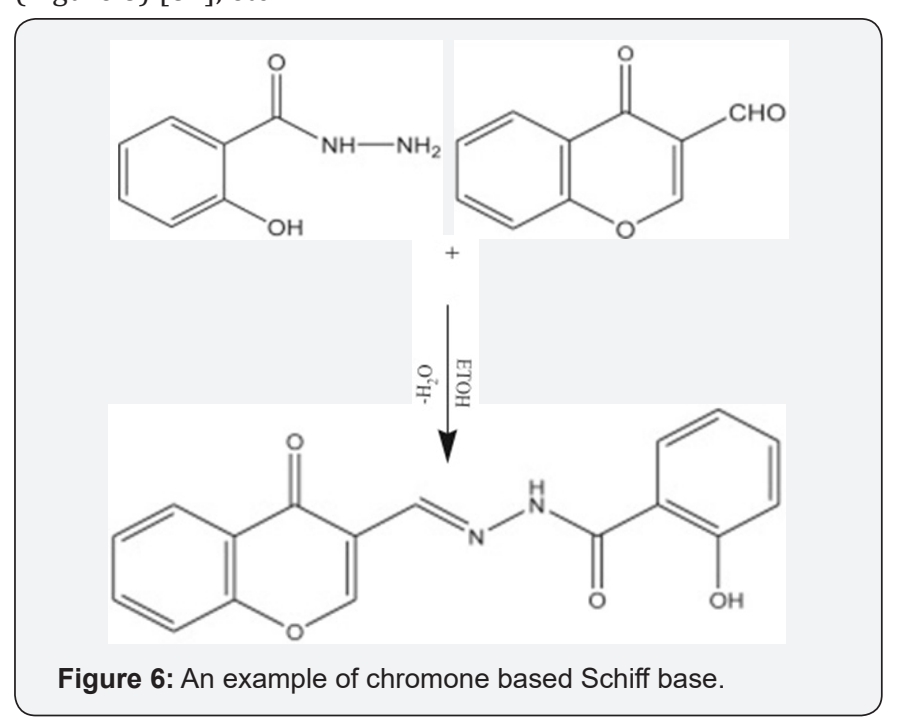

Another important aspect of the antioxidant studies is the strength of a complex not to undergo ROS generation to render a mechanistic action without harming a normal mammalian cell e.g., Ag complex of 1, 10-phenanthroline [65] has shown an interesting behaviour in this context.

\section{Sugar and Urea Derivative Based Complexes}

Urea derivatives bonding through the nitrogen, sulfur and oxygen atoms to the central metal ion form an important class of biologically active ligands. They have been receiving considerable attention due to their pharmacological properties, anti tubercular activity, antiviral potentiality, activity against protozoa small pox and certain kinds of tumour [66]. The chelating characters of thiosemicarbazone have been studied very widely with different metal ions, their complexes with transition and non transition elements were reported.

The ability of sugars to sequester metals is of current interest in the possible development of metal chelates for clinical use and as models for biologically important compounds. Amino sugars form Schiff base with salicylaldehyde and other aromatic aldehydes and only few reports of transition metal complexes of these ligands have been found. Metal chelation could be a rational therapeutic approach for interdicting Alzheimer's disease (AD) pathogenesis. Amyloid plaques that are clusters of proteins and metal ions accumulated between neurons (nerve cells) in Alzheimer's patients' brains. Enhancing the targeting and efficacy of metal-ion chelating agents through sugar appended ligand is a recent strategy in the development of the next generation of metal chelators.

\section{Conclusion}

From the overall survey it has been established that biomolecules impart great effects in metallic systems to develop molecules of interest. Metallopharmaceuticals are engaged in designing heme-oxygenase and nitric oxide synthase models to bring forth highly demanded gasotransmitter efficiency applicable at various bio-essential routes. Under these circumstances scientific community should fabricate bioconjugated systems to form compounds of human beneficial and multi-purposeful.

\section{References}

1. Gerber HP, Senter PD, Grewal IS (2009) Antibody drug-conjugates targeting the tumor vasculature: Current and future developments, MAbs 1(3): 247-253.

2. Paterson BM, Alt K, Jeffery CM, Price RI, Jagdale S, et al. (2014) EnzymeMediated Site-Specific Bioconjugation of Metal Complexes to Proteins: Sortase-Mediated Coupling of Copper-64 to a Single-Chain Antibody, Angew Chem Int Ed Engl 53(24): 6115-6119.

3. Us Patent, Bioconjugates of metal complexes of nitrogen-containing macrocyclic ligands. US 7407645 B2.

4. Lippard SJ, Berg JM (1994) Principles of Bioinorganic Chemistry. University Science Books, Mill Valley, California 23: 115.

5. Z Lu, Yang L (2003) Crystal structure and nuclease activity of mono (1,10-phenanthroline) copper complex: J Inorg Biochem 95(1): 31-36.

6. Altamirano EB, Gonzalez-Peerez JM, Lazarte DC, Carballo R, Castineiras A, et al. (2003) A structural evidence for the preferential coordination of the primary amide group versus the unionised carboxyl group: synthesis, molecular and crystal structure, and properties of [Cu(HADA)2], a new copper(II) bis-chelate(H2ADA=N(2-carbamoylmethyl)iminodiacetic acid). Inorganic Chemistry Communications 6: 71-73.

7. Caballero AB, Salas JM, Moreno MS (2014) Metal-Based Therapeutics for Leishmaniasis: A chapter in "Leishmaniasis-Trends in Epidemiology, Diagnosis and Treatment", book edited by David M. Claborn.

8. Khedekar S, Rukkudin G, Ravishankar B, Prajapati P (2016) Antidiabetic activity of traditional Indian gold containing preparation: Shadguna Balijarita Makaradhwaja on streptozotocin induced diabetic rats. J Intercult Ethnopharmacol 5(2): 162-167.

9. Balan K, Qing W, Wang Y, Liu X, Palvannan T, et al. (2016) Antidiabetic activity of silver nanoparticles from green synthesis using Lonicera japonica leaf extract. RSC Advances 46: 40162-40168.

10. Sadler PJ, Guo Z (1998) Metal complexes in medicine: Design and mechanism of action, Pure \& Appl. Chem 70(4): 863-871.

11. Akinremi CA, Obaleye JA, Amolegbe SA, Adediji JF, Bamigboye MO (2012) Biological activities of some Fluoroquinolones-metal complexes. Int J Med Biomed Res 1(1): 24-34. 


\section{Novel Approaches in Drug Designing \& Development}

12. Lippard SJ, Bertini I, Grany HB, Valentine JS (1994) Bioinorganic Chemistry: Metals in Medicine. University Science Books 1: 207.

13. Farrell NP (1989) Transition Metal Complexes as Drugs and Chemotherapeutic Agents. James BR, Ugo R, et l. (Eds.), Academic Press: Dordrecht, USA 11: 809-834.

14. Lawal A, Obaleye JA (2007) Synthesis, characterization and antibacterial activity of aspirin and paracetamolmetal complexes. Biokemistri 19(1): 9-15.

15. Rafique S, Idrees M, Nasim A, Akbar H, Athar A (2010) Transition metal complexes as potential therapeutic agents: Biotechnology and Molecular Biology Reviews 5(2): 38-45.

16. Dar AM, Khan MA, Mir S, Gatoo MA (2016) DNA Binding, Cleavage Activity, Molecular Docking, Cytotoxicity and Genotoxicity Studies of Newly Synthesized Copper Based Metal Complexes: Pharm Anal Acta $7: 2$

17. Desoize B (2004) Metals and Metal Compounds in Cancer Treatment. Anticancer Res 24(3a): 1529-1544.

18. Ceresa C, Nicolini G, Semperboni S, Bossi M, Requardt H, et al. (2014) In-vitro anticancer activity and neurotoxicity of novel heavy metalbased anticancer complexes: Int J Anticancer E 119.

19. Jurowska A, Jurowski K, Szklarzewicz J, Buszewski B, Kalenik T, et al. (2016) Molybdenum metallopharmaceuticals candidate compounds - the "renaissance" of molybdenum metallodrugs. Current Med Chem 23(29): 3322-3342.

20. Motswainyana WM, Ajibade PA (2015) Anticancer Activities of Mononuclear Ruthenium (II) Coordination Complexes. Advances in Chemistry 2015: 1-21.

21. Khana T, Ahmad R, Joshia S, Khan AR (2015) Anticancer potential of metal thiosemicarbazone complexes: A review Pelagia Research Library Der Chemica Sinica 6(12): 1-11.

22. Choudharya A, Sharma R, Nagara M, Mohsin M, Meena HS (2011) Synthesis, characterization and antioxidant activity of some transition metal complexes with terpenoid derivatives. Journal of the Chilean Chemical Society 56(4): 911-917.

23. Patel KS, Patel JC, Dholariya HR, Patel VK, Patel KD (2012) Synthesis of $\mathrm{Cu}(\mathrm{II}), \mathrm{Ni}(\mathrm{II}), \mathrm{Co}(\mathrm{II})$, and $\mathrm{Mn}(\mathrm{II})$ Complexes with Ciprofloxacin and Their Evaluation of Antimicrobial, Antioxidant and Anti-Tubercular Activity. Open Journal of Metal 2(3): 49-59.

24. Reddy HK, lee SM, Seshaiah K, Babu KR (2012) Synthesis, characterization of thiosemicarbazone metal complexes and their antioxidant activity in different in vitro model systems. J Serb Chem Soc 77(2): 229-240.

25. Boligon AA, Machado MM, Athayde ML (2014) Technical Evaluation of Antioxidant Activity. Med Chem 4: 517-522.

26. Khan MSS, Salam MA, Rosenani SM, Haque A, Asif M, et al. (2016) Synthesis, cytotoxicity, andlong-termsingle dose anti-cancer pharmacological evaluation of dimethyltin(IV)complex of N(4) methylthiosemicarbazone (having ONS donor ligand). Cogent Biology 2(1).

27. Mruthyunjayaswamy BHM, Nagesh GY, Ramesh M, Priyanka B, Heena B (2015) Synthesis, characterization and antioxidant activity of Schiff base ligand and its metal complexes containing thiazole moiety. Der Pharma Chemica 7(10): 556-562.

28. Danish M, Raza MA, Ilyas T, Sharif A, Anjum N (2015) Metal Complexes and Organotin(IV) Compounds of Cefixime and their Biological Study. Med Chem 5.

29. Rajendran M, Ravichandran R, Devapiriam (2012) Molecular Modeling Study of Quercetin and their Metal Complexes. International Journal of Computer Applications 50: 5-22.
30. Patel KS, Patel JC, Dholariya HR, Patel VK, Patel KD (2012) Synthesis of $\mathrm{Cu}(\mathrm{II}), \mathrm{Ni}(\mathrm{II}), \mathrm{Co}(\mathrm{II})$ and $\mathrm{Mn}(\mathrm{II})$ Complexes with Ciprofloxacin and Their Evaluation of Antimicrobial, Antioxidant and Anti-Tubercular Activity. Open Journal of Metal 2: 49-59.

31. Naik KHK, Ashok B, Naik N (2013) Synthesis, Characterization and Biological Properties of Metal Complexes with an N/S/O Functionalized Ligands. Int J Pharm and Chem Sci 2(3): 1403-1407.

32. Li J, Yu K, Bai J, Zhang H, Chao J (2014) Synthesis, characterization and free radical scavenging activity of apigenin with or without magnesium(II). Oxid Antioxid Med Sci 3(3): 231-235.

33. Kumara VA, Saralac Y, Kumar MVJ, Reddya MS, Reddya AV, et al. (2014) Synthesis and Spectral Characterization of Nickel (II) and Copper (II) Complexes of 4-Chlorobenzaldehydethiosemicarbazone (CBTSC) and Evaluation of Antioxidant Activity. Res J Pharm BC Sci 5(5): 96-104.

34. Panhwar QK, Memon S (2014) Synthesis, Characterization and Antioxidant Activity of Rutin Complexes. Pak J Anal Environ Chem15(2): 60-70.

35. Tyurin VY, Moiseeva AA, Shpakovsky DB, Milaeva ER (2015) The electrochemical approach to antioxidant activity assay of metal complexes with dipicolylamine ligand, containing 2,6-di-tertbutylphenol groups, based on electrochemical DPPH-test. J of Electro analytical Chem 756: 212-221.

36. Turan N, Bursa E, Colak N, Buldurun K (2015) Investigation of Synthesis, Structural Characterization, Antioxidant Activities and Thermal Properties of $\mathrm{Zn}(\mathrm{II}), \mathrm{Fe}(\mathrm{II})$ and $\mathrm{Mn}(\mathrm{II})$ Complexes with Thiophene-Carboxylate Ligand. J Chem and Biochem 3(2): 13-29.

37. Warner SD, Sheng H, Haberle JB (2016) Oxidants, antioxidants and the ischemic brain. The J Exp Biol 207: 3221-3231.

38. Derek Lowe (2016) Putting chemistry back in biology.

39. Krishnan G, Bharate SS, Awasthi A, Verma R, Mishra G, et al. (2016) Antidiabetic potential of polyherbal formulation DB14201: Preclinical development, safety and efficacy studies. Journal of Ethnopharmacology 197: 218-230.

40. Domingo JL, Vanadium compounds for the treatment of human diabetes mellitus: A scientific curiosity? A review of thirty years of research. Food and Chemical Toxicology 278: 30225.

41. Lazarenkoa OP, Rzoncaa SO, Suvab LJ, Lecka-Czernika B (2006) Netoglitazone is a PPAR-gamma ligand with selective effects on bone and fat. Bone 38(1): 74-84

42. Xie X, Zhou X, Chen W (2015) L312, a novel PPAR ligand with potent anti-diabetic activity by selective regulation, Biophysical Acta 185062 72.

43. Cetinkalp S (2013) Can an oral antidiabetic (rosiglitazone) be of benefit in leukemia treatment. Saudi Pharmaceutical Journal 23: 14-21.

44. Carvalho HDO (2016) Hypoglycemic effect of formulation containing hydro ethanolic extract of Calophyllum brasiliense in diabetic rats induced by streptozotocin. British Journal of Pharmacology 272: 1-6.

45. Deopa D (2013) Current Updates On Anti-Diabetic Therapy. Journal of Drug Delivery \& Therapeutics 3(6): 121-126.

46. Thompson KH, Jessica Chiles, Yuen VG, Tse J, McNeill JC, et al. (2004) Comparison of anti-hyperglycemic effect amongst vanadium, molybdenum and other metal maltol complexes. Journal of Inorganic Biochemistry 98(2004): 683-690.

47. Budiasih KS, Pertiwi KR (2015) Pre Clinical Study of Cr(III)based Hypoglicemic Supplementin-Type 2 Diabetic Rats, Current Breakthrough in Pharmacy Materials and Analyses. Proceeding - ICB Pharma II.

48. El-Megharbel SM (2015) Synthesis, spectroscopic, structural and thermal characterizations of vanadyl(IV) adenine complex prospective 
as antidiabetic drug agent, Spectrochimica Acta Part A. Molecular and Biomolecular Spectroscopy 135: 850-864.

49. Briones D (2015) Highly Active Anti-Diabetic Metal-Organic Framework, Crystal Growth \& Design is published by the American Chemical Society 1155 Sixteenth Street NW, Washington DC.

50. Zong-Lian D (2007) Synthesis and Study of Antidiabetic Properties of the Neodymium Complexes with N5-[o-(un)Substituted Benzoyl]N1,N1- dimethylbiguanide. Chinese Journal of Chemistry 25(12): 1919-1923.

51. Grazula M (2009) Biological activity of metal ions complexes of chromones, coumarins and flavones. Coordination Chemistry Reviews 253(1): 2588-2598.

52. Maanvizhi S, Narayanaswamy R (2014) Molecular docking analysis of embelin and its metal complexes as human aldose reductase (HAR) inhibitor. Der Pharmacia Lettre 6 (2): 165-168.

53. Silvana Ficarra, Ester Tellone, Davide Pirolli, Annamaria Russo, Davide Barreca, et al. (2016) Insights into the properties of the two enantiomers of trans- $\delta$-viniferin, a resveratrol derivative: antioxidant activity, biochemical and molecular modeling studies of the interactions with haemoglobin. Molecular Biosystems 4.

54. Fevzi Topal, Meryem Nar, Hulya Gocer, Pınar Kalin, Umit M. Kocyigit (2015) Antioxidant activity of taxifolin: an activity-structure relationship, J Enzyme Inhibition, Journal of Medicinal Chemistry 31(4): 1475-6374.

55. Sani U, Baba MA (2016) Synthesis, Characterization, Antimicrobial and Antioxidant Studies of 2-[(2-Hydroxyphenyl) Methylidene] Hydrazine-1- Carboxamide And Its Metal (Ii) Complexes. Bayero Journal of Pure and Applied Sciences 9(1): 206-212.

56. Hua Zhang Rong Tsao (2016) Dietary polyphenols, oxidative stress and antioxidant and anti-inflammatory effects. Covalent organic frameworks.

57. Perontsis S, Hatzidimitriou AG, S Perontsis (2016) Nickel-diflunisal complexes: synthesis, characterization, in-vitro antioxidant activity and interaction with DNA and albumins. Journal of Inorganic Biochemistry 162: 9-21.
58. Vishwakarma PK, Mir JM, Maurya RC (2016) Pyrone-based Cu(II) complexes, their characterization, DFT based conformational drift from square planar to square pyramidal geometry and biological activities. Journal of Chemical Sciences 128(4): 511-522.

59. Hasi QM, Fan Y, Yao XQ (2016) Synthesis, characterization, antioxidant and antimicrobial activities of a bidentate Schiff base ligand and its metal complexes, Polyhedron.

60. Turnaturi R, Oliveri V, Vecchio G (2016) Biotin-8-hydroxyquinoline conjugates and their metal complexes: exploring the chemical properties and the antioxidant activity, Polyhedron.

61. Koc S, Ali Köse D, Emre Avcı, Kazim Kose (2016) Synthesis and Thermal Characterization of p-Coumaric Acid Complexes of CoII, NiII, CuII and ZnII Metal Cations and Biological Applications. Hittite Journal of Science and Engineering 3(1): 15-22.

62. Yasser K, Monem A, Saeyda A (2016) Design of new metal complexes of 2-(3-amino-4,6-dimethyl-1Hpyrazolo[3,4-b]pyridin-1-yl)acetohydrazide: Synthesis, characterization, modelling and antioxidant activity. Journal of Molecular Structure 1127: 386-396.

63. Saif M, Hoda F, El-Shafiy (2016) Synthesis, characterization, and antioxidant/cytotoxic activity of new chromone Schiff base nanocomplexes of $\mathrm{Zn}(\mathrm{II}), \mathrm{Cu}(\mathrm{II}), \mathrm{Ni}(\mathrm{II})$ and $\mathrm{Co}(\mathrm{II})$, Journal of Molecular Structure 1118: 75-82.

64. Laura Thornton, Vidya Dixit, Assad LO, Ribeiro TP, Queiroz DD, et al. (2016) Water-soluble and photo-stable silver(I) dicarboxylate complexes containing 1,10-phenanthroline ligands: Antimicrobial and anticancer chemotherapeutic potential, DNA interactions and antioxidant activity. J Inorg Biochem 159: 120-32.

65. Maurya RC, Malik BA, Mir JM, Vishwakarma PK, Rajak DK, et al. Nickel (II) complexes of ONS donor Schiff base ligands: synthesis, combined DFT-experimental characterization, redox, thermal and in-vitro biological investigation. Journal of Coordination Chemistry 68: 29022922.

66. Maurya RC, Malik BA, Mir JM, Sharma AK (2014) Synthesis, characterization, thermal behavior, and DFT aspects of some oxovanadium (IV) complexes involving ONO-donor sugar Schiff bases. Journal of Coordination Chemistry, 67(18): 3084-3106.

\begin{tabular}{l} 
Your next submission with Juniper Publishers \\
will reach you the below assets \\
- Quality Editorial service \\
- Swift Peer Review \\
- Reprints availability \\
- E-prints Service \\
- Manuscript Podcast for convenient understanding \\
- Global attainment for your research \\
- Manuscript accessibility in different formats \\
( Pdf, E-pub, Full Text, Audio) \\
- Unceasing customer service \\
Track the below URL for one-step submission \\
https://juniperpublishers.com/online-submission.php \\
\hline
\end{tabular}

